\title{
Avaliação de fatores de vulnerabilidade para a infecção da AIDS em pacientes residentes no município de Santa Maria, RS
}

\author{
Evaluation of factors of vulnerability to infection of AIDS in patients residing in \\ the municipality of Santa Maria, RS
}

\author{
Elisandra dos Santos', Lorena Vicini", Adriano Mendonça Souza'"I
}

\begin{abstract}
RESUMO
A AIDS é uma causa de preocupação à sociedade e tem sido um desafio para as autoridades de saúde, pois esta atinge um número cada vez maior de pessoas, muitos desses tornam-se doentes crônicos, os quais necessitam de auxílio do governo para seu tratamento, tornando-se assim, um grande problema de saúde pública. Este trabalho tem como objetivo compreender o perfil epidemiológico da AIDS em Santa Maria e apresentar a Análise de Correspondência múltipla como uma ferramenta exploratória de dados. Realizou-se um estudo descritivo, que relaciona o número de pessoas notificadas com AIDS com a região de residência em Santa Maria, por meio de uma técnica multivariada. Foram analisados 893 casos de AIDS notificados em Santa Maria de 2007 a 2013. Quando avaliado os mapas de correspondência múltipla, verificou-se relação entre o número de mulheres e a região sul do município, já os homens estão relacionados a região leste. Ainda observou-se que existe uma relação entre o modo de transmissão: mulheres relação sexual com homens e homens relação sexual com mulheres e bissexual. A técnica de análise de correspondência múltipla proporcionou a verificação de várias relações entre as variáveis sócio demográficas e os fatores de vulnerabilidade.
\end{abstract}

Palavras-chave: Síndrome da imunodeficiência adquirida; Perfil epidemiológico; Análise de correspondência múltipla.

\begin{abstract}
AIDS is causes concern to society and has been a challenge for health authorities, as it affects an increasing number of people, many of whom become chronically ill, who need government assistance for its treatment, thus becoming a major public health problem. This work aims to understand the epidemiological profile of AIDS in Santa Maria and present the Multiple Correspondence Analysis as an exploratory data tool. A descriptive study was carried out, which relates the number of people notified with AIDS to the region of residence in Santa Maria, using a multivariate technique. We analyzed 893 cases of AIDS reported in Santa Maria of 2007 to 2013. When the multiple correspondence maps were evaluated, there was a relationship between the number of women and the southern region of the municipality, whereas men are related to the eastern region. It was also observed that there is a relationship between the mode of transmission: women sexual intercourse with men and men sexual intercourse with women and bisexual. The multiple correspondence analysis technique provided the verification of several relationships between socio-demographic variables and vulnerability factors.
\end{abstract}

Keywords: Acquired immunodeficiency syndrome; Epidemiological profile; Multiple correspondence analysis.

\footnotetext{
'E-mail: elisandrafaccim@gmail.com.

"E-mail: vicini22@gmail.com.

IIIE-mail: amsouza.sm@gmail.com.
} 


\section{INTRODUÇÃO}

Nos anos 80 , surge uma doença até então desconhecida dos médicos que atinge um número reduzido de pessoas, porém, o "ataque" da mesma ao ser humano é agressivo e leva a morte em pouco tempo, surge então os primeiros casos de AIDS.

O primeiro caso conhecido de infecção e morte por AIDS aconteceu em 1977, e foi diagnosticado por uma médica dinamarquesa que estudava o vírus ebola na África (MARQUES, 2008). A partir do surgimento de novos casos dessa doença, o CDC Vigilância Epidemiológica dos Estados Unidos - passa a investigar quais seriam as causas, sintomas e sinais nos pacientes infectados, definindo assim um perfil de paciente propenso a adquirir a nova síndrome. Em 1982, passou-se a ter conhecimento dos meios de transmissão do vírus, que pode ser por qualquer tipo de contato com o sangue, por relação sexual ou por uso conjunto de drogas injetáveis.

Foi descoberto em 1984 que a AIDS é fase final da doença, causada pelo do retrovírus HIV no organismo (LABOISSIÈRE, 2011). A história natural da infecção pelo HIV pode ser apresentada em três fases: 1- infecção aguda; 2- fase assintomática e 3fase sintomática, e, estima-se que na ausência de qualquer intervenção terapêutica, a mediana de progressão da infecção aguda à fase sintomática (período de incubação) seja de aproximadamente 10 anos (KUO, et. al., 1991).Surgiram assim, diversos estudos, já que essa doença estava causando a morte rápida de várias pessoas, e ainda não se sabia como controlar a disseminação. Por volta dos anos 1983 e 1984, pesquisadores americanos e franceses conseguem isolar o vírus que causa a doença e a partir daí verificaram que este tinha uma grande variabilidade genética e exigiria um esforço enorme dos pesquisadores na luta para encontrar uma solução para o problema.

Em 1995, o total mundial relatado de casos de AIDS era de 1 milhão, e calculavase que havia o total de 18 milhões de adultos com HIV+e 1,5 milhões crianças de HIV+. A AIDS se transformou na principal causa de morte da faixa etária entre 25-44 anos nos EUA. E estimava-se que o número de mortes global da doença já chegava aos 9 milhões.

Segundo a World Health Organization (WHO), já morreram 21,8 milhões de pessoas por causa da doença e há 36,1 milhões de portadores do vírus espalhados pelo 
mundo. Cerca de $90 \%$ destes vivem em lugares pobres. A epidemia colocou vários países da África Central em estado de calamidade pública: em muitas regiões calculase que cerca de $20 \%$ a $30 \%$ da população esteja infectada (VARELLA; 2011).

Os primeiros casos de AIDS registrados no Brasil foram identificados em 1982, quando sete pacientes masculinos com práticas homo e bissexuais foram diagnosticados. Diante dessa constatação amplamente divulgada pelos meios de comunicação, a sociedade brasileira construiu núcleos de resistências sociais e culturais, provocando atitudes de discriminação, medo e de preconceito (SANCHES, 1999).

Em um estudo realizado por Rodrigues Junior e Castilho (2004), os casos diagnosticados no Brasil de 1991 a 2000 caracterizavam-se por serem do sexo masculino, com alto nível sócio econômico e por pertencerem às categorias de transmissão homossexuais/bissexuais, além dos portadores de hemofilia e os receptores de sangue.

No ano 2000, após 20 anos de epidemia no Brasil, o Ministério da Saúde relata ter gasto 303 milhões de dólares na compra de medicamentos para controlar o vírus da AIDS e que foram beneficiados cerca de 87.500 brasileiros em 2001, onde foram despendidos $R \$ 515,2$ milhões com essa finalidade (MS, 2002c). O custo médio ponderado em dólar, por paciente/ano de terapia anti-retroviral, vem caindo. Em 1996, foi de US\$ 3.810/paciente/ano; em 2000, US\$ 3.320; e até junho de 2001, US\$ 2.530/paciente/ano (MS, 2002c).

Em 2005, segundo os dados oficiais do governo brasileiro, eram 150 mil pacientes vivendo com a doença. Nesses dados, não estão presentes os pacientes que possuem apenas o vírus HIV, mas sim os pacientes que já estão acometidos da doença e que são atendidos em alguma rede do governo de distribuição de medicamentos. Em 2012, segundo o Departamento de DST, AIDS e Hepatites Virais/SVS/MS, eram 656.701 casos de AIDS, com uma média de 36 mil casos novos por ano. Além disso, a doença é considerada responsável por aproximadamente 11,5 mil óbitos por ano.

Após 30 anos da doença, os cientistas ainda não encontraram a cura; existe, hoje, apenas formas de preveni-la. Na rede pública existe disponível um medicamento que 
é indicado para pós exposição, que deve ser tomado rigorosamente todos os dias durante 30 dias e após ser feito o teste para verificar a existência ou não do vírus HIV. Este medicamento deve ser iniciado até 72 horas depois da exposição. Conforme orientação do Ministério da Saúde, a Profilaxia Pós-Exposição é uma medida que consiste no início do uso de antirretrovirais até 72 horas decorridas de uma provável exposição ao vírus HIV. Ela é utilizada basicamente um duas situações: em caso de risco de contaminação de profissionais de saúde na atividade laboral (devido a acidentes), e em casos de relações sexuais quando ocorre falha nas medidas de prevenção (a partir de uma avaliação médica).

Outro medicamento, que ainda não está disponível no Brasil, está sendo testado nos EUA, que é chamado pré exposição, consiste em tomar um comprimido durante toda a vida, sendo que este medicamento tem a eficácia de 92\% de não infecção, caso exista a exposição ao vírus.

Devido ao fato de ainda não existir a cura da AIDS, toda a pesquisa epidemiológica em relação à doença é focada nos fatores de vulnerabilidade, prevenção e modificação do cenário, com o intuito de diminuir a infecção. O termo "contexto social" se refere aos fatores demográficos, socioeconômicos, macroeconômicos, sócio-políticos e ambientais. Características econômicas e demográficas e outros aspectos estruturais das sociedades, supra-individuais, exercem um importante papel de modulação sobre as variáveis epidemiológicas e os comportamentos individuais, incluindo comportamentos sexuais, transmissão de infecções sexualmente transmissíveis e outros agravos à saúde (ADIMORA; SCHOENBACH, 2005).

Devido às alterações no perfil epidemiológico e à grande diversidade da infraestrutura da saúde pública e distribuição dos serviços e profissionais desta área nas diferentes regiões do município, necessita-se de uma detalhada análise dos casos de AIDS, para que se tenha conhecimento dos locais em que se encontram os maiores focos da doença, possibilitando, dessa forma, um maior monitoramento dos casos e uma avaliação do contexto em que estão inseridos, principalmente quando se trata de doenças infecciosas emergentes, como é o caso da AIDS. 
Portanto, faz-se de grande importância apontar fatores que sejam relacionados a características individuais e de extensão da epidemia de AIDS. Este trabalho tem como objetivo compreender o perfil epidemiológico da AIDS em Santa Maria e apresentar a Análise de Correspondência múltipla como uma ferramenta exploratória de dados, no período de 2007 a 2013, buscando, com isso, contribuir de forma mais eficiente na abrangência e compreensão sobre o processo saúde/doença baseado nas características individuais e contextuais da população.

\section{REFERENCIAL TEÓRICO}

\subsection{Cenário da AIDS no Brasil}

“Segundo dados do Programa Conjunto das Nações Unidas para HIV/Aids (UNAIDS, 2010), o Brasil situa-se entre os quatro países do mundo com maior número de casos notificados; entretanto, quando consideradas as incidências relativas, encontra-se entre $040^{\circ}$ e $50^{\circ}$ posto no ranking mundial.

De 1980 a 2011, o Brasil notificou cerca de 608.230 casos da doença, sendo considerado o único país de Terceiro Mundo a ter um sólido programa de políticas públicas voltado para o controle e tratamento da epidemia (MINISTÉRIO DA SAÚDE; 2012).

De acordo com o levantamento realizado pela World Health Organization (WHO), em 2011, havia 34 milhões de pessoas com HIV+ no mundo, sendo que 3,3 milhões eram de crianças e adolescentes com menos de 15 anos. Em 2011, foram 1,7 milhão de mortes pela doença. A cada dia, estima-se que mais 7 mil pessoas são infectadas, sendo que somente 3.950 iniciam a terapia com antirretrovirais.

A nível global, o Brasil teve redução no número de novos casos de HIV: eram 35.979 em 2009 e caíram para 34.212 em 2010, bem como entre 2009 e 2010, a estimativa de pessoas infectadas pelo HIV esteve estável (0,6\% da população) e o número de óbitos diminuiu (Folha de São Paulo, 2011). De acordo com o Boletim Epidemiológico HIV-AIDS (2014), houve uma queda de 13\% na mortalidade por AIDS no Brasil entre 2000 e 2013, dentre os óbitos em decorrência da doença, neste período, $198.534(71,4 \%)$ ocorreram entre homens e 79.655 (28,6\%) entre mulheres. 
Conforme o Boletim da AIDS de 2014, a taxa de detecção do HIV+ se manteve estável na população, com números por volta de 20,2 casos a cada 100 mil habitantes. No entanto, no Sudeste este número vem apresentando queda, ao passo que sobem na região Norte e especialmente no Sul, onde em 2012 foram registrados 39.185 casos novos da doença.

De acordo com o Boletim Epidemiológico de 2012, cerca de 734 mil pessoas viviam com HIV e AIDS no país. Deste total, 80\% (589 mil) foram diagnosticadas. Desde os anos 80, foram notificados 757 mil casos de AIDS no país. Em 2013, cresceu 29\% o número de pessoas em tratamento de AIDS no Brasil, comparado com o ano anterior. De janeiro a outubro de 2013, 61.221 iniciaram a terapia para controlar o HIV, de acordo com o Ministério da Saúde (2014), no entanto, segundo o Ministro da Saúde, Arthur Chioro (2014), 200 mil pessoas ainda não têm acesso ao tratamento e 150 mil pessoas têm HIV positivo, mas não sabem que possuem a doença.

Segundo o Boletim epidemiológico de AIDS de 2018, de 1980 a junho de 2018, foram identificados 926.742 casos de AIDS no Brasil. O país tem registrado, anualmente, uma média de 40 mil novos casos de aids nos últimos cinco anos. $O$ número anual de casos de aids vem diminuindo desde 2013, quando atingiu 43.269 casos; em 2017 foram registrados 37.791 casos. A distribuição proporcional dos casos de aids, identificados de 1980 até junho de 2018, mostra uma concentração nas regiões Sudeste e Sul.

O Rio Grande do Sul é o principal estado quando se trata de detecção de casos de AIDS. A magnitude da epidemia de AIDS no Rio Grande do Sul (RS) possui características que a diferem daquelas observadas nos demais estados brasileiros. A taxa de detecção de novos casos no RS é o dobro da nacional, e Porto Alegre é a capital com a maior taxa de detecção do país (SECRETARIA ESTADUAL DE SAÚDE, 2014). De acordo com o Boletim Epidemiológico HIV-Aids de 2012, o Rio Grande do Sul registrou a maior taxa de detecção do país, com 41,4 casos por 100 mil habitantes. $O$ índice é maior que o dobro da média nacional, que é de 20,2 registros da doença. O segundo colocado é o Amazonas, com 29,2. A eficácia das políticas de detecção populacional do vírus em nosso Estado explica o elevado índice dos diagnósticos. 
O Rio Grande do Sul lidera o ranking do surgimento de novos casos de AIDS, são 27,7 por 100 mil habitantes, segundo dados do Ministério da Saúde de 2012. No ranking por capitais, Porto Alegre se destaca com 99,8 casos por 100 mil habitantes, enquanto Florianópolis, segunda da lista, registra 57,9/100 mil. O sul do Brasil concentra 23\% dos casos de Aids, com apenas $14 \%$ da população total do país. O dado chama atenção do Ministério da Saúde, que promete investimentos na região para reverter essa estatística. O número faz parte do Boletim Epidemiológico DST AIDS (2014), que ainda em acordo com o boletim, todas as 10 cidades que lideram a lista de maior incidência da doença estão no Sul (Porto Alegre (RS), Alvorada (RS), Balneário Camboriú , Uruguaiana (RS), Sapucaia do Sul (RS), Criciúma (SC), Biguaçu (SC), Pinhais (PR), Florianópolis (SC) e Canoas (RS)).

Quando se trata de doenças infecciosas, como é o caso da AIDS, não se pode pensar em contaminação de forma presente, já que muitos pacientes só procuram ajuda quando os primeiros sintomas se manifestam. Para que o diagnóstico da doença seja mais rápido, a Secretaria Estadual da Saúde (SES), tem como objetivo introduzir nos Serviços de Assistência Especializada (SAE) e nas Unidades de Pronto Atendimento (UPAs), a Profilaxia Pré-Exposição (PREP) e expandir para a atenção básica a Profilaxia Pós-Exposição (PEP), que já é oferecida desde 2010 nos SAE. O estudo terá o prazo de um ano e deve começar no primeiro trimestre de 2014. O principal auxílio é a distribuição de medicamentos antirretrovirais a públicos prioritários de pessoas não portadoras do HIV, mas que apresentam riscos elevados de infecção, como homens que fazem sexo com outros homens e profissionais do sexo, entre outros.

Em Santa Maria há um total de 1.586 casos de HIV/AIDS até o ano de 2012. Na maioria dos casos, a doença foi transmitida por relação sexual sem camisinha (PADOIN; DE PAULA, 2013). Nos últimos 10 anos (2007 a 2016), Santa Maria teve um crescimento de $262 \%$ dos casos de HIV entre homens e $175 \%$ entre as mulheres. No ano passado, o município chegou ao recorde da década com a notificação de 185 novos casos do gênero masculino e 110 do feminino. A maior ocorrência, em ambos os sexos, é entre jovens de 20 a 29 anos (DIARIO DE SANTA MARIA, 2017). 


\subsection{Análise de Correspondência}

A análise de correspondência é uma técnica estatística exploratória utilizada para verificar associações ou similaridades entre variáveis qualitativas ou variáveis contínuas categorizadas Clausen (MOTA, 2007). A relação entre as categorias das variáveis é investigada sem que se precise designar uma estrutura causal nem assumir a priori uma distribuição de probabilidades, sendo apropriada no estudo de dados populacionais no sentido de uma técnica não inferencial Greenacre (MOTA, 2007).

A técnica de análise de correspondência múltipla utilizada permite verificar as relações entre estudo de fatores de risco e determinadas características do perfil de uma população em estudo. Com isso, verifica-se quais grupos possuem os mesmos fatores de risco para a aplicação de políticas públicas.

A técnica de Análise de Correspondência foi introduzida por Hirschfeld (1935). Inicialmente, a sua utilização foi na avaliação de dados na área da psicologia, por se tratar de uma técnica que utiliza dados qualitativos. Em meados dos anos 60, esta técnica voltou a ser utilizada como ferramenta de análise de dados na França e, a partir de então esta técnica vem sendo amplamente utilizada em diversas áreas do conhecimento.

Segundo KONP (2008), a análise de correspondência (AC) é uma técnica de análise exploratória de dados adequada para analisar tabelas de duas entradas (ANCOR) ou tabelas de múltiplas entradas (HOLMS), levando em conta algumas medidas de correspondência entre linhas e colunas. A concepção geral da AC, entre outros aspectos, é que nela se permite a inclusão de variáveis categóricas, ou seja, apropriada para dados nominais.

A partir dos princípios geométricos da análise de correspondência, é possível representar dentro do espaço euclidiano as distâncias entre os pontos linha e/ou coluna resultante da associação entre as variáveis da tabela de contingência. "Assim, tem-se o gráfico denominado "mapa de correspondência" ou "mapa perceptual" que facilita a visualização das relações existentes entre as variáveis (LOURENÇO, 1997). O objetivo desta técnica é mostrar geometricamente as variáveis, suas categorias e os 
objetos observados na base de dados em um espaço de baixa dimensão, de modo que a proximidade no espaço indica associação entre as linhas e colunas" (GREENACRE, 2010).

A análise de correspondência pode ser considerada como um caso especial da análise de componentes principais (CP), porém aplicada a dados categóricos organizados em tabelas de contingência e não a dados contínuos. O problema é análogo a encontrar o maior componente principal de um conjunto de I observações e J variáveis, com modificações devido à ponderação das observações e à métrica ponderada.

A análise de correspondência inicia-se com a construção da Tabela 1 de contingencia genérica, baseado em CZERMAINSKI (2004), definida a seguir:

Tabela 1 - Composição de uma tabela de contingência genérica $N(I, J)$

\begin{tabular}{|c|c|c|c|c|c|}
\hline & $B$ & & & & \\
\hline A & 1 & 2 & & j & Total linha \\
\hline 1 & $n_{11}$ & $n_{12}$ & $\ldots$ & $n_{1 j}$ & $n_{1+}$ \\
\hline 2 & $n_{21}$ & $n_{22}$ & $\ldots$ & $n_{2 j}$ & $n_{2+}$ \\
\hline$\ldots$ & $\ldots$ & $\ldots$ & $\ldots$ & $\ldots$ & $\ldots$ \\
\hline I & $n_{i 1}$ & $n_{i 2}$ & $\ldots$ & $n_{i j}$ & $n_{i+}$ \\
\hline Total coluna & $n_{+1}$ & $n_{+2}$ & $\ldots$ & $N_{+j}$ & N \\
\hline
\end{tabular}

Seja então:

- Total da linha: ${ }^{n_{i+}}=\sum_{j} n_{i j}$

- Total da coluna: $n_{j+}=\sum_{j} n_{i j}$

- Total da geral das frequências observadas: $N=\sum_{i} \sum_{j} n_{i j}$

Com base na Tabela 1 de contingência, pode-se construir a matriz de correspondência, que será calculada por meio das frequências relativas da tabela de contingência. Assim, cada linha da matriz de correspondências P será considerada um vetor. As frequências relativas serão calculadas por meio:

$$
p_{i j}=\frac{n_{i j}}{N} \text {, para todo i:1 a I e j=1 a J }
$$


Quadro 1 - Matriz de correspondência

\begin{tabular}{|l|l|l|l|l|l|}
\hline & $\mathrm{B}$ & 2 & $\cdots$ & $\mathrm{j}$ & \\
\hline $\mathrm{A}$ & 1 & $n_{12} / N$ & $\cdots$ & $n_{1 j} / N$ & $p_{1+}=n / /$ \\
\hline 1 & $n_{11} / N$ & $n_{22} / N$ & $\cdots$ & $n_{2 j} / N$ & $p_{2+}=n / N$ \\
\hline 2 & $n_{21} / N$ & $\vdots$ & $\vdots$ & $\vdots$ & \\
\hline$\vdots$ & $\vdots$ & $n_{i 2} / N$ & $\cdots$ & $n_{i j} / N$ & $p_{i+}=n / N$ \\
\hline $\mathrm{i}$ & $n_{i 1} / N$ & $p_{+2}=n_{+2} / N$ & $\cdots$ & $p_{+j}=n_{+j} / N$ & 1 \\
\hline Total da coluna & $p_{+1}=n_{+1} / N$ & $p$ & \\
\hline
\end{tabular}

Para as frequências relativas das marginais será da seguinte forma:

- Linha: $p_{i+}=\frac{n_{i+}}{N}$

- Coluna: $p_{+j}=\frac{n_{+j}}{N}$

Essas frequências relativas são denominadas massas, o vetor de massas de linhas é definido da seguinte forma:

$r=\left[p_{1+} ; p_{2+; ; ;} p_{i+}\right]=\frac{1}{n}$

O vetor de massas de colunas:

$$
c=\left[p_{+1} ; p_{+2 ; \cdots ;} p_{+j}\right]=\frac{n_{i}}{n}
$$

O vetor perfil da linha é definido da seguinte forma:

$$
a_{i}=\left[\frac{n_{i 1}}{n_{i+}} ; \frac{n_{i 2}}{n_{i+}} ; \cdots ; \frac{n_{i j}}{n_{i+}}\right]
$$

O vetor perfil da coluna é definido da seguinte forma:

$$
b_{i}=\left[\frac{n_{1 j}}{n_{+j}} ; \frac{n_{2 j}}{n_{+j}} ; \cdots ; \frac{n_{i j}}{n_{+j}}\right]
$$

Definem-se as distâncias entre perfis linha não pela métrica euclidiana usual, mas pela métrica euclidiana ponderada, chamada métrica ou distância qui-quadrado:

$$
\begin{aligned}
& d_{c}\left(a_{i}, a_{i}{ }^{\prime}\right)=\left(a_{i}-a_{i}{ }^{\prime}\right)^{\prime} D_{c}^{-1}\left(a_{i}-a_{i}{ }^{\prime}\right) \\
& \sum_{j=1}^{j} \frac{\left(n_{i j} / n_{i+1}-n_{i j} / n_{i++}\right)^{2}}{\left(n+n_{+j} / n\right)}
\end{aligned}
$$


ou seja, $d_{c}\left(a_{i}, a_{i}^{\prime}\right)$ é a distância euclidiana entre ai e ai' na métrica Dc (ponderada por $\left.D_{c}\right)$, onde $D c$ é a matriz diagonal de elementos $c_{j}=n_{+j} / n(j=1, \ldots, J)$. O vetor $c=\left[c_{1}, c_{2}\right.$ ....c ] ]', proporções marginais de colunas ou massas de colunas, é também chamado de perfil linha médio ou centróide dos perfis linha. Analogamente, as distâncias entre perfis colunas são obtidas na métrica $D_{r}$ (ponderada por $D_{r}$ ), que é a matriz diagonal das proporções marginais de linhas $r i=n_{i+/} n(i=1, \ldots, l)$, que compõem o vetor $r$, o centroide dos perfis coluna ou vetor de massa de linhas (RIBEIRO, 2011).

Quadro 2 - Síntese da análise de correspondência múltipla (adaptado de Claussen, 1998)

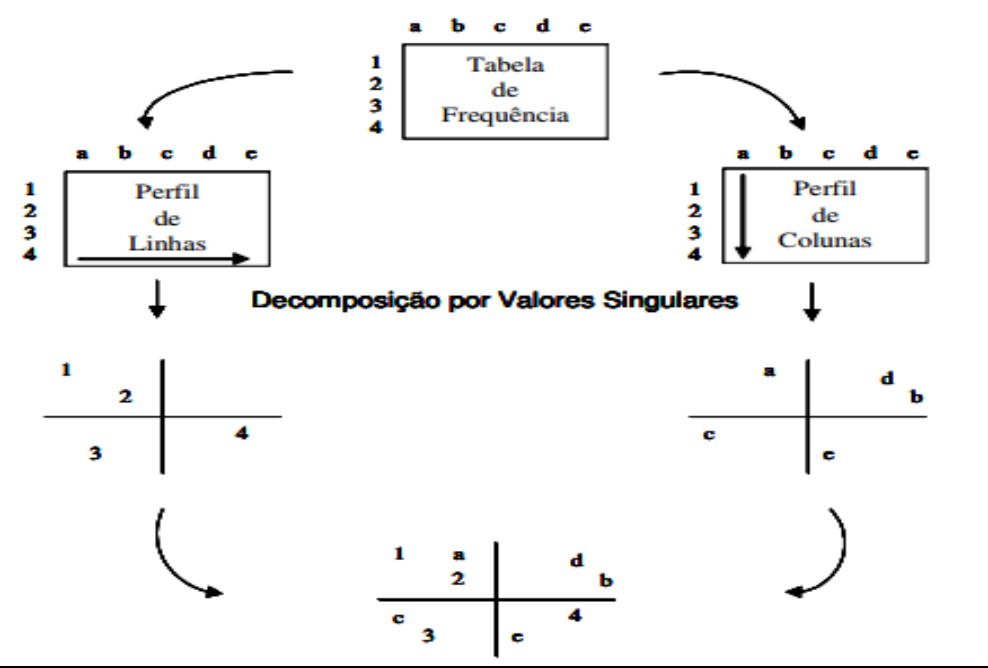

\section{METODOLOGIA}

Este trabalho será desenvolvido com as informações sobre AIDS, que é uma doença de notificação compulsória por meio dos dados do Sistema de Notificação de Agravos do município de Santa Maria. Os dados brutos estão disponibilizados no site da Secretaria de Saúde do município, no período de janeiro de 2007 a dezembro de 2013. A avaliação será realizada com base na análise multivariada de dados, com a aplicação da Análise de Correspondência Múltipla para responder aos objetivos propostos.

\subsection{Caracterização do local de pesquisa}

O local da pesquisa foi a cidade de Santa Maria que está situada na região central do estado do Rio Grande do Sul, possuindo uma área correspondente a $1.780 \mathrm{~km}^{2}$, é a quinta cidade mais populosa do Rio Grande do Sul, com uma população, em 2010, de 
261.031 pessoas, onde o centro urbano detinha $94 \%$ das pessoas. Do ponto de vista da distribuição espacial, em Santa Maria (RS), desde 1940, a população urbana já era superior à rural (VIERO; FIGUEIREDO, 2012). Para classificar o município em regiões administrativas foi utilizado o mapa da divisão urbana e o mapa com os limites distritais de Santa Maria.

\subsection{População}

A população do estudo será composta pelas notificações de casos de AIDS no período de janeiro de 2007 a dezembro de 2013, cujos indivíduos residem no município de Santa Maria, RS e foram diagnosticados com AIDS no período em análise. Serão excluídas da amostra as notificações de AIDS que, após a repetição de novos testes, não tiveram o diagnóstico confirmado.

\subsection{Dados Utilizados na pesquisa}

As variáveis encontram-se disponíveis no sistema SINANNET, sendo elas notificadas neste sistema, porém, não consta nenhuma identificação pessoal dos indivíduos portadores da AIDS. Os fatores sociodemográficos dos indivíduos investigados na pesquisa foram: idade, sexo, se gestante, raça, escolaridade, bairro, ocupação, transmissão vertical, transmissão sexual, uso de drogas, tratamento/hemotransfusão, transfusão sanguínea, acidente com material biológico e evolução da doença.

$\mathrm{Na}$ ficha de notificação dos pacientes com AIDS - Adulto (maiores de 13 anos) são apresentados dois critérios, para que se considere os indivíduos com a doença AIDS, são eles: o Critério Rio de Janeiro / Caracas, que apresenta doenças, sinais e sintomas, com uma determinada pontuação para cada uma delas, em que é considerado como caso de AIDS quando o indivíduo apresentar evidência laboratorial de infecção pelo HIV e pelo menos um somatório de 10 pontos, de acordo com a seguinte escala de sinais, sintomas ou doenças apresentadas a seguir: 
Quadro 3 - Fatores de risco ou doenças oportunistas de pacientes notificados com AIDS em Santa Maria, RS - Critério Rio de Janeiro/Caracas

\begin{tabular}{|l|c|}
\hline Critério Rio de Janeiro/Caracas & Pontuação \\
\hline Sarcoma de Kaposi & 10 \\
\hline Tuberculose Disseminada/extra pulmonar/não cavitária & 10 \\
\hline Candidose Oral ou leucoplasia pilosa & 5 \\
\hline Tuberculose Pulmonar Cavitária ou não especificada & 5 \\
\hline Herpes Zoster em indivíduo menor ou igual a 60 anos & 5 \\
\hline Disfunção no sistema nervoso central & 5 \\
\hline Diarreia igual ou maior a 1 mês & 2 \\
\hline $\begin{array}{l}\text { Febre maior ou igual a 38 } \\
1 \text { mês }\end{array}$ & 2 \\
\hline Caquexia ou perda de peso maior que 10\% & 2 \\
\hline Astenia maior ou igual a 1 mês & 2 \\
\hline Dermatite persistente & 2 \\
\hline Anemia e/oi linfopenia e/ou trombocitopenia & 2 \\
\hline Tosse persistente ou qualquer pneumonia & 2 \\
\hline $\begin{array}{l}\text { Linfadenopatia maior ou igual a 1cm, maior ou igual a } \\
\text { dois sítios extra-inguinais e por tempo maior ou igual a } \\
1 \text { mês }\end{array}$ & \\
\hline
\end{tabular}

Outro critério utilizado é o CDC Adaptado, segundo o qual o CDC está relacionado ao Centers for Disease Control and Prevention, órgão que estabeleceu a primeira definição de caso de AIDS no mundo, em 1982. Este critério está relacionado, basicamente, a doenças em que, para ser considerado indivíduo portador de AIDS, o mesmo pode ter teste laboratorial para o HIV não realizado ou de resultado desconhecido e que, eliminadas outras causas de imunodeficiência, apresentar pelo menos uma das seguintes doenças indicativas de AIDS diagnosticada definitivamente: 
Quadro 4 - Fatores de risco ou doenças oportunistas de pacientes notificados com AIDS em Santa Maria, RS - Critério CDC adaptado

\begin{tabular}{|l|}
\hline Critério CDC adaptado \\
\hline Câncer Cervical Invasivo \\
\hline Candidose de Esôfago \\
\hline Candidose de traquéia, brônquios ou pulmão \\
\hline Citomegalovirose (exceto fígado, baço ou linfonodos) \\
\hline Criptococose extrapulmonar \\
\hline Criptosporidiose intestinal crônica $>1$ mês \\
\hline Herpes Simples mucocutânea $>1$ mês \\
\hline Histoplasmose disseminada \\
\hline Isosporidiose intestinal crônica $>1$ mês \\
\hline Leucoencefalopatia multifocal progressiva \\
\hline Linfoma não Hodgkin e outros linfomas \\
\hline Linfoma primário do cérebro \\
\hline Micobacteriose disseminada exceto tuberculose e hanseníase \\
\hline Pneumonia por Pneumocystis carinii \\
\hline Reativação da doença de Chagas (meningoencefalite e/ou miocardite) \\
\hline Salmonelose (sepse recorrente não-tifóide) \\
\hline Toxoplasmose Cerebral \\
\hline Contagem de linfócitos T CD4+ menor que 350 cel/mm \\
\hline
\end{tabular}

$\mathrm{Na}$ avaliação da ficha de notificação, pode-se observar que a maior parte dos dados são representados por variáveis categóricas, havendo poucas variáveis contínuas, sendo atribuídas a estas categorias para que seja possível analisá-las. Nessa análise, leva-se em conta que as categorias que possuem frequências baixas poderão influenciar na determinação das coordenadas principais na análise de correspondência múltipla (LE ROUX; ROUANET, 2004). Portanto, inicialmente foi necessária uma análise das variáveis em estudo, levando em consideração alguns critérios expostos:

a) Número de respostas não informadas (ausentes) inferior a 5\% do total;

b) Número de respostas "Não se Aplica" inferior a 20\% do total de respostas;

c) Haver pelo menos 5\% em cada uma das possíveis respostas para a variável.

\subsection{Análise Estatística}

A fim de melhor atender aos objetivos propostos, realizou-se um estudo descritivo e exploratório, de abordagem quantitativa, uma vez que esta possibilita maior aproximação com o cotidiano e as experiências vividas pelos próprios sujeitos (MINAYO, 1993). De acordo com Gil (2008), as pesquisas descritivas possuem como objetivo a descrição das características de uma população, fenômeno ou de uma 
experiência. Por exemplo, quais as características de um determinado grupo em relação a sexo, faixa etária, renda familiar, nível de escolaridade, entre outros. Conforme Neto (2006), “pesquisa exploratória estabelece critérios, métodos e técnicas para a elaboração de uma pesquisa e visa oferecer informações sobre o objeto desta e orientar a formulação de hipóteses".

Este estudo foi realizado em duas etapas: a primeira incluiu a descrição das características sócio-demográficas e os fatores de risco que estão vinculados aos pacientes notificados com AIDS. Na segunda etapa, buscou-se explorar relações conjuntas entre os fatores socioeconômicos, demográficos, fatores de risco e as regiões de residência dos pacientes notificados por meio da análise de correspondência.

\section{APRESENTAÇÃO E ANÁLISE DOS RESULTADOS}

No período de 2007 a 2013 foram notificados nos Serviços de Atendimentos a pacientes com AIDS em Santa Maria, 1.298 novos casos, sendo que 893 (69\%) são residentes no município de Santa Maria, os quais serão o foco deste estudo.

$\mathrm{Na}$ pesquisa realizada verificou-se que a maioria das notificações eram de indivíduos do sexo masculino 518 (58,0\%), de raça branca 657 (76,7\%), seguidos de pacientes negros 94 (10,9\%) e de cor parda 82 (9,6\%). A idade variou entre 14 e 89 anos, com média de 38,08 $( \pm 11,01)$ anos. As mulheres diagnosticadas possuíam uma média de idade de $36,67( \pm 11,43)$ anos e os homens uma média de idade de 39,12 $( \pm 10,59)$ anos. Quanto à escolaridade, apenas 634 fichas de notificação possuíam esta informação, houve ausência de aproximadamente 259 (30\%) de informação desta variável. Dentre as notificações que possuíam esta informação, apenas 16 (2,5\%) declaram-se analfabetos e 618 (97,5\%) afirmaram ter estudado, sendo que destes, 326 $(51,4 \%)$ possuem ensino fundamental incompleto e apenas $36(4,0 \%)$ tem ensino superior completo.

Analisando a população de 375 mulheres diagnosticadas, verificou-se que quando analisada a variável referente a ser gestante, nota-se que 68 (18,2\%) dos dados eram perdidos, pois foi notificado como "não se aplica" ou "ignorado". Dentre as 307 mulheres que responderam este item, 31 (10,1\%) relataram estar grávida. Destas, $17(54,8 \%)$ disseram estar no segundo trimestre de gestação e 11 (35,5\%) relataram 
estar no terceiro trimestre de gestação. A taxa de transmissão do HIV de mãe para filho durante a gravidez, sem qualquer tratamento, pode ser de $20 \%$. Porém, se a gestante seguir todas as recomendações médicas, a possibilidade de infecção do bebê reduz para níveis menores que $1 \%$.

Dentre os pacientes diagnosticados, 393 (44,1\%) não possuíam sua ocupação profissional. Já em relação às mulheres, a maioria era dona de casa $(59,4 \%)$, seguindose ocupações de baixa qualificação, sendo elas, como empregadas domésticas 25 $(11,4 \%)$, estudantes eram $15(6,8 \%)$, aposentadas $10(4,6 \%)$ e desempregadas $10(4,6 \%)$. Dentre os homens, o maior índice de infecção acontece nos desempregados $46(16,4 \%)$, seguido de pedreiros 24 (8,6\%), aposentados $22(7,9 \%)$ e estudantes são $7(16,1 \%)$.

Quanto à zona de moradia, verificou-se que dentre os que possuíam esta informação, 748 (85,8\%) eram da zona urbana, $111(12,7 \%)$ da periurbana e apenas 13 $(1,5 \%)$ da zona rural.

Em relação ao quadro clínico dos pacientes foi avaliado por meio da contagem de linfócitos CD4+. A maioria deles apresentava contagem de CD4+ inferior a 350 células $/ \mathrm{mm}^{3} 835$ (93,6\%) em que o tratamento anti-retroviral é recomendado, para que não haja o acometimento de doenças oportunistas. Apenas $43(4,8 \%)$ apresentaram à carga viral acima de 350 células $/ \mathrm{mm}^{3}$. Neste estágio, somente monitora-se o paciente. E em 14(1,6\%) dos pacientes diagnosticados, não foi avaliada a carga viral.

Todos os pacientes apresentaram alguma doença oportunista relacionada ao HIV/AIDS. Entre as doenças oportunistas, destacou-se a Toxoplasmose Cerebral 48 (5,5\%), seguida da Tuberculose Pulmonar Cavitária ou não especificada 34 (3,9\%). Dentre os sintomas, os que mais acometeram os pacientes foram: perda de peso maior de $10 \%$ ou caquexia $305(34,8 \%)$, astenia $270(30,9 \%)$, tosse persistente $234(26,7 \%)$, febre 248 (28,3\%) e diarreia igual ou maior que um mês $220(25,1 \%)$.

A principal forma de infecção, de acordo com os pacientes diagnosticados, foi por relação sexual $786(88,0 \%)$, sendo que destes, 409 (45,8\%), foi por meio de relação sexual com homens, $332(42,2 \%)$ relação sexual com mulheres e $45(5,8 \%)$, relação sexual com homens e mulheres. Já, na avaliação do uso de drogas, observou-se que $156(17,5 \%)$, relataram ser por relação sexual ou por uso de drogas e $53(5,9 \%)$ foi 
exclusivamente pelo uso de drogas. Logo, relacionado ao uso de droga tem-se um 209 $(23,4 \%)$. Ainda, $7(1,1 \%)$ dos pacientes disseram transmissão vertical, mas destes, 6 $(85,7 \%)$ citaram também a relação sexual como possível meio de infecção. Outra forma de transmissão notificada foi transfusão sanguínea, que correspondeu a 10 (1,2\%), dentre estes, 8 (80,0\%) também estão relacionados a transmissão sexual.

Entre as mulheres, a forma de infecção mais comum relatada foi relação sexual com homens $336(89,6 \%)$, seguida de relação com mulheres $12(3,2 \%)$, com homens e mulheres $3(0,8 \%)$.

Dentre os homens, a forma de infecção mais comum relatada foi relação sexual com mulheres $320(61,8 \%)$, seguida de relação com homens $73(14,1 \%)$ e com homens e mulheres $42(8,1 \%)$.

A Figura 1 representa a pirâmide etária dos indivíduos residentes em Santa Maria diagnosticados com AIDS, no período de 2007 a 2013. A distribuição dos casos é regular entre os sexo feminino e masculino, e a faixa etária com maior número de casos é de 30-39 anos. Porém, observada a faixa de 30 a 49 anos, o percentual no sexo masculino é de $67,9 \%$ e feminino $55,9 \%$.

Figura 1 - Pirâmide etária dos casos de AIDS, em Santa Maria, no período de 2007 a 2013

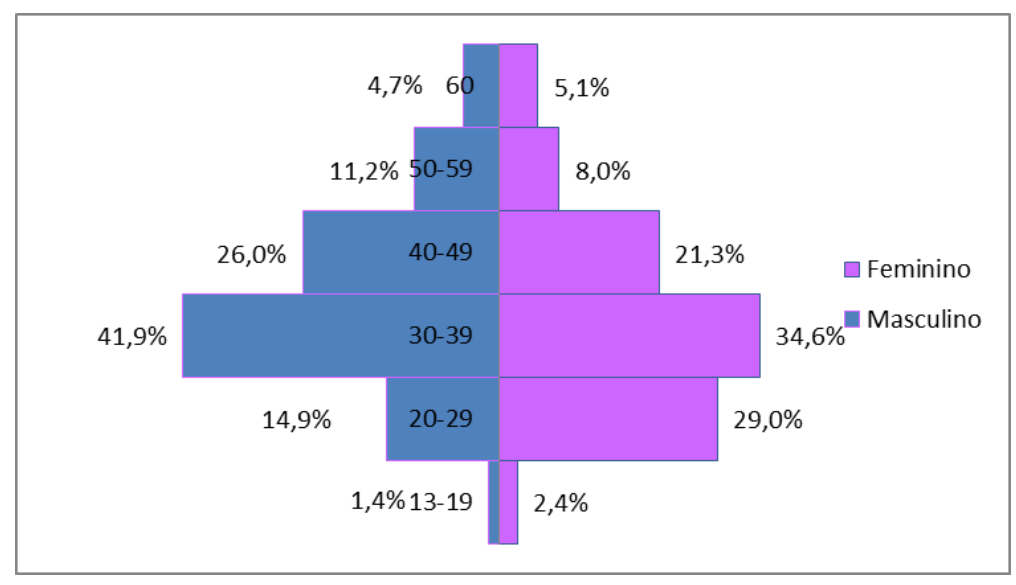

Na Figura 2 é apresentada a distribuição do número de casos de AIDS notificados no município de Santa Maria RS, segundo as regiões administrativas. 
Figura 2 - Mapa da distribuição dos casos de AIDS notificados no município de Santa Maria, no período de 2007 a 2013, por região administrativa

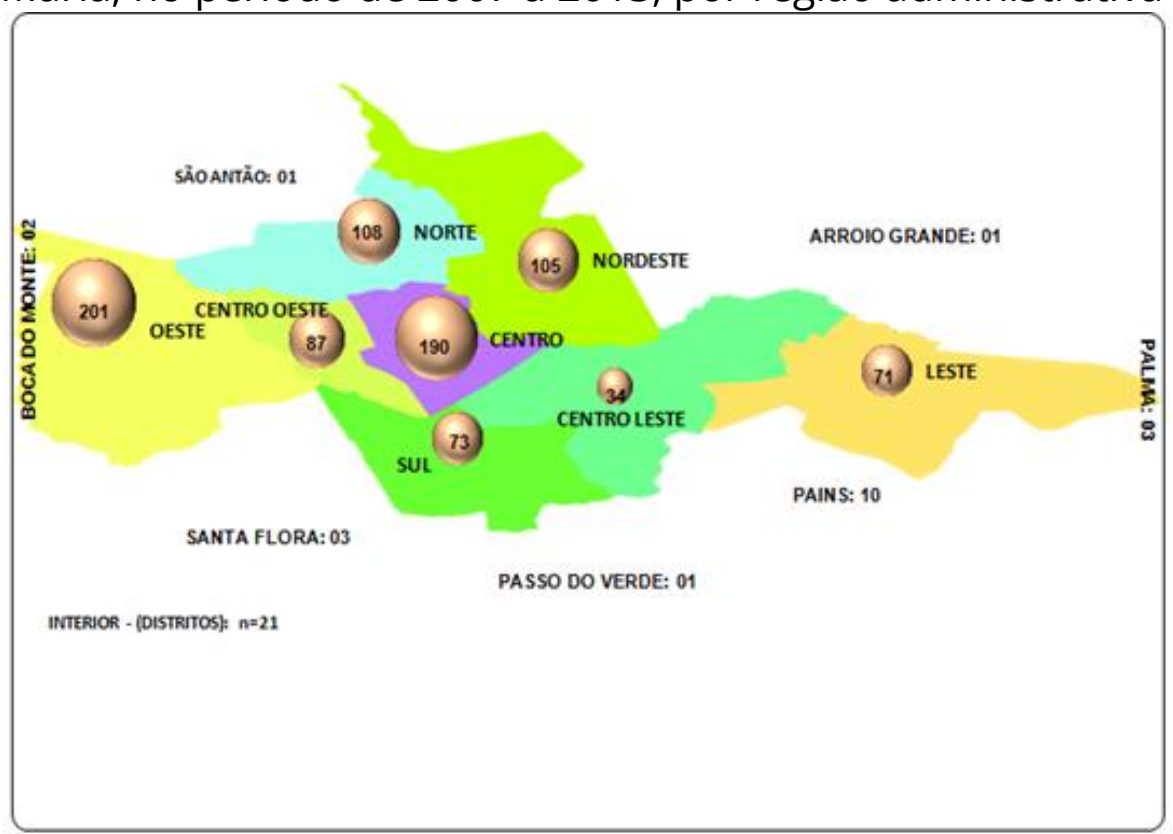

Legenda: Centro: Centro, bairros: Bonfin, Nonoai, Ns ${ }^{\mathrm{a}}$. Sra ${ }^{\mathrm{a}}$. de Fátima, $\mathrm{Ns}^{\mathrm{a}}$ de Lourdes, $\mathrm{Ns}^{\mathrm{a}}$. Sra ${ }^{\mathrm{a}}$. de Rosário e $\mathrm{Ns}^{\mathrm{a}}$. Sr ${ }^{\mathrm{a}}$ de Medianeira, Norte: Bairros: Carolina, Caturrita, Chácara das Flores, Divina Providencia, Ns ${ }^{\mathrm{a}}$. Sra . do Perpétuo Socorro e Salgado Filho, Nordeste: Bairros: Campestre do Menino Deus, Itararé, KM3, Menino Jesus, Ns ${ }^{\mathrm{a}}$. Sra ${ }^{\mathrm{a}}$. das Dores e Presidente João Goulart, Leste: Bairro Camobi, Centro-Leste: Bairros: João Luiz Pozzobon, Cerrito, Pé-Platano e São José, Sul: Bairro: Lorensi, Tomazetti e Urlândia, Centro-Oeste: Bairros: Duque de Caxias, Noal, Passo D' Areia, Patronato e Uglione, Oeste: Bairros: Agro-Industrial, Boi Morto, Juscelino Kubitschek, Pinheiro Machado, Renascença, Nova Santa Marta, São João e Tancredo Neves.

Dentre os 893 casos notificados, $3(0,3 \%)$ deles não possuíam dados sobre o bairro de residência, apenas a cidade.

A região com maior incidência de casos de AIDS na cidade de Santa Maria é a Região Oeste, 201 (22,5\%). Nesta região, a maioria dos casos diagnosticados foram no Bairro Tancredo Neves 57 (28,3\%), seguido da Nova Santa Marta 54(26,7\%) e Bairro Pinheiro Machado 37(18,4\%).

Na Tabela 2, é apresentada a distribuição dos casos de AIDS no município de Santa Maria em relação ao ano de notificação e à região de residência do indivíduo notificado. 
Tabela 2 - Número de casos de AIDS em relação aos anos, por região administrativa

\begin{tabular}{|c|c|c|c|c|c|c|c|c|c|}
\hline \multirow[t]{2}{*}{ Regiões } & & \multicolumn{7}{|c|}{ Ano de notificação } & \multirow[t]{2}{*}{ Total } \\
\hline & & 2007 & 2008 & 2009 & 2010 & 2011 & 2012 & 2013 & \\
\hline \multirow[t]{2}{*}{ Centro } & $\mathrm{N}$ & 19 & 25 & 18 & 51 & 30 & 20 & 27 & 190 \\
\hline & $\%$ & 21,11 & 17,01 & 19,57 & 21,52 & 26,55 & 16,00 & 30,34 & 21,28 \\
\hline \multirow[t]{2}{*}{ Centro leste } & $\mathrm{N}$ & 7 & 3 & 3 & 8 & 5 & 8 & 0 & 34 \\
\hline & $\%$ & 7,8 & 2,0 & 3,3 & 3,4 & 4,4 & 6,4 & 0,0 & 3,8 \\
\hline \multirow[t]{2}{*}{ Centro oeste } & $\mathrm{N}$ & 10 & 16 & 9 & 20 & . & 13 & 10 & 87 \\
\hline & $\%$ & 11,1 & 10,9 & 9,8 & 8,4 & 8,0 & 10,4 & 11,2 & $9,7 \%$ \\
\hline \multirow[t]{2}{*}{ Interior } & $\mathrm{N}$ & 0 & 1 & 2 & 1 & 2 & 4 & 2 & 21 \\
\hline & $\%$ & 0,0 & 0,7 & 2,2 & 4,2 & 1,8 & 3,2 & 2,2 & $2,4 \%$ \\
\hline \multirow[t]{2}{*}{ Leste } & $\mathrm{N}$ & 8 & 10 & 8 & 1 & 8 & 11 & 9 & 71 \\
\hline & $\%$ & 8,9 & 6,8 & 8,7 & 7,2 & 7,1 & 8,8 & 10,1 & $8,0 \%$ \\
\hline \multirow{2}{*}{ Nordeste } & $\mathrm{N}$ & 10 & 22 & 12 & 30 & 13 & 13 & 5 & 105 \\
\hline & $\%$ & 11,1 & 15,0 & 13,0 & 12,7 & 11,5 & 10,4 & 5,6 & $11,8 \%$ \\
\hline \multirow[t]{2}{*}{ Norte } & $\mathrm{N}$ & 11 & 20 & 12 & 2 & 19 & 17 & 6 & 108 \\
\hline & $\%$ & 12,2 & 13,6 & 13,0 & 9,7 & 16,8 & 13,6 & 6,7 & $12,1 \%$ \\
\hline \multirow[t]{2}{*}{ Oeste } & $\mathrm{N}$ & 19 & 39 & 1 & 5 & 22 & 32 & 20 & 20 \\
\hline & $\%$ & 21,1 & 26,5 & 16,3 & 22,8 & 19,5 & 25,6 & 22,5 & $22,5 \%$ \\
\hline \multirow[t]{2}{*}{ Sul } & $\mathrm{N}$ & 6 & 10 & 13 & 2 & 5 & 7 & 9 & 73 \\
\hline & $\%$ & 6,7 & 6,8 & 14,1 & 9,7 & 4,4 & 5,6 & 10,1 & $8,2 \%$ \\
\hline ota & & 90 & 146 & 92 & 236 & 113 & 125 & 88 & 890 \\
\hline
\end{tabular}

Em relação aos resultados da Tabela 2, observa-se que a maioria dos casos de AIDS foram diagnosticados no ano de 2010, correspondendo a 236 (26,5\%). Observase ainda que a região oeste compreende $22,5 \%$ dos casos de AIDS notificados, em Santa Maria, no período de 2007 a 2013, seguida da região centro $(21,8 \%)$, sendo que essas duas regiões representam $44,3 \%$ do total de casos notificados nesse município.

Na Figura 03 verifica-se a distribuição dos óbitos referente aos indivíduos notificados com AIDS, segundo os anos de notificação. 
Figura 3 - Número de óbitos nos pacientes notificados com AIDS, no município de Santa Maria, no período de 2007 a 2013

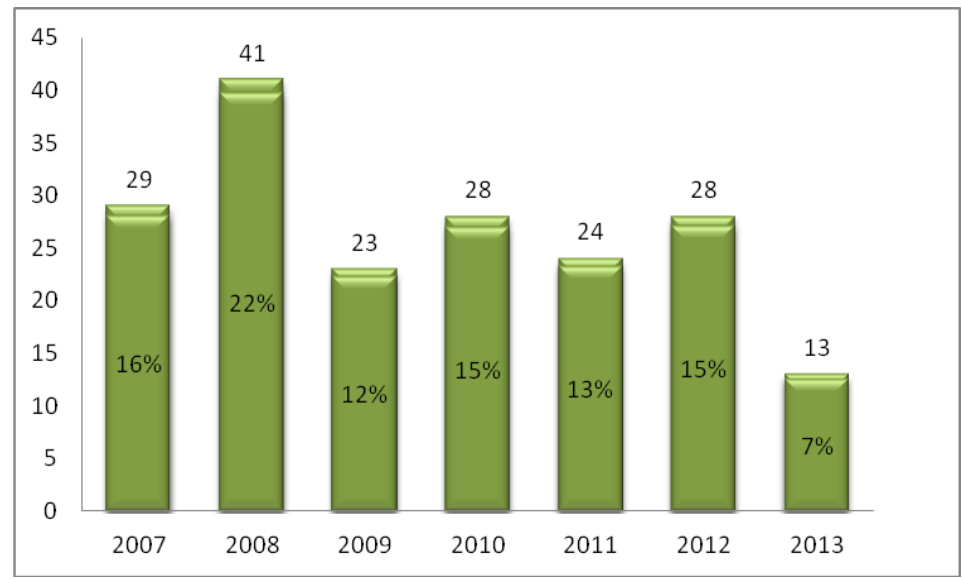

Conforme a Figura 3 observa-se que no período de 2007 a 2013, no município de Santa Maria, ocorreram 186 óbitos dentre a população de pacientes com AIDS. Verificase ainda que no ano de 2008 ocorreu o maior número de óbitos dentre os pacientes diagnosticados com AIDS, residentes no município de Santa Maria; no ano de 2013 ocorreu o menor percentual em todo o período.

Foi aplicada a análise de correspondência múltipla nos dados referentes aos pacientes notificados com AIDS no município de Santa Maria, RS. Foram considerados alguns cenários diferentes, observando em cada mapa de correspondência algumas variáveis de maior importância para o estudo e, com isso, foi verificado o quão relacionadas estão, e obtidas suas características.

Figura 4 - Mapa de Correspondência Múltipla - Variáveis: gênero, idade, raça e região

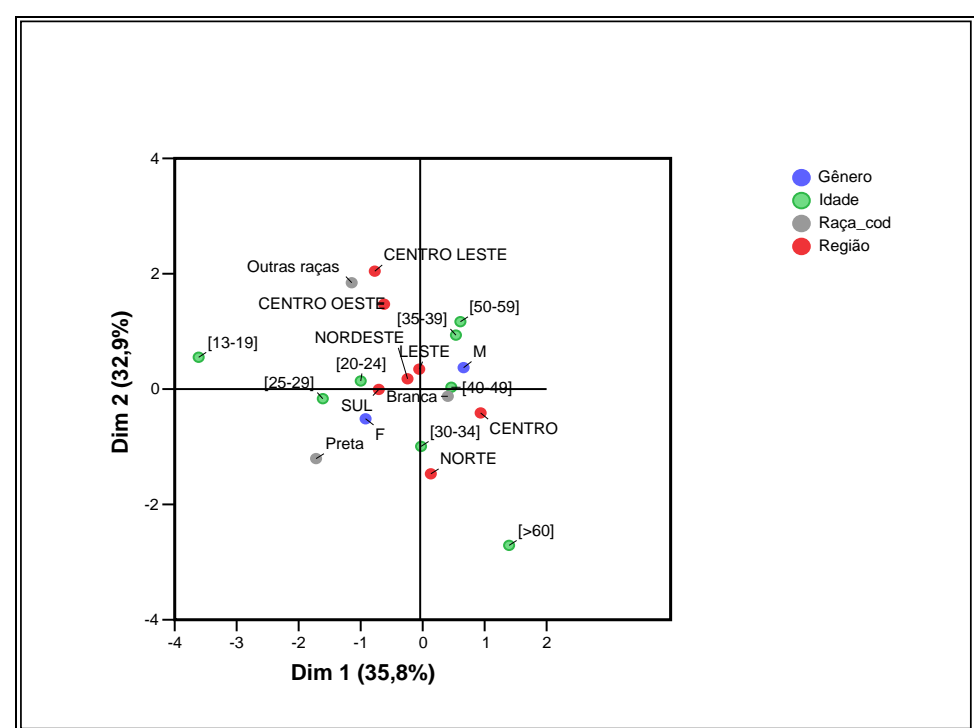

Legenda: [Gênero: F (feminino) e M (masculino)], [idade: faixas etárias],

[raça: outras (parda, amarela e indígena)], [região: divisão administrativa por regiões da cidade]. 
A Figura 4 ilustra a análise de correspondência dos pacientes notificados com AIDS levando em consideração as variáveis: gênero, idade, raça e região de residência do paciente. O gráfico da análise de correspondência em duas dimensões representa $68,7 \%$ da dimensionalidade total dos dados. A dimensão 1 é influenciada pela variável idade, seguida do gênero. A dimensão 2 também tem sua maior parcela influenciada pela idade e depois da região. Observa-se que as mulheres estão associadas à raça preta e na região sul do mapa. Nota-se que a faixa etária que compreende indivíduos acima de 60 anos está em contraposição a faixa etária [13 - 19] anos. Além disso, a faixa etária >60 está concentrada na região norte e a [13-19] no centro oeste. O sexo masculino está associado à região leste, nas faixas etárias [40 - 59] anos e de raça branca.

A Figura 5 apresenta o mapa de correspondência entre as variáveis: gênero, provável modo de transmissão - drogas e sexual e a região dos indivíduos.

Figura 5 - Mapa de correspondência múltipla - Variáveis: gênero, provável modo de transmissão e região

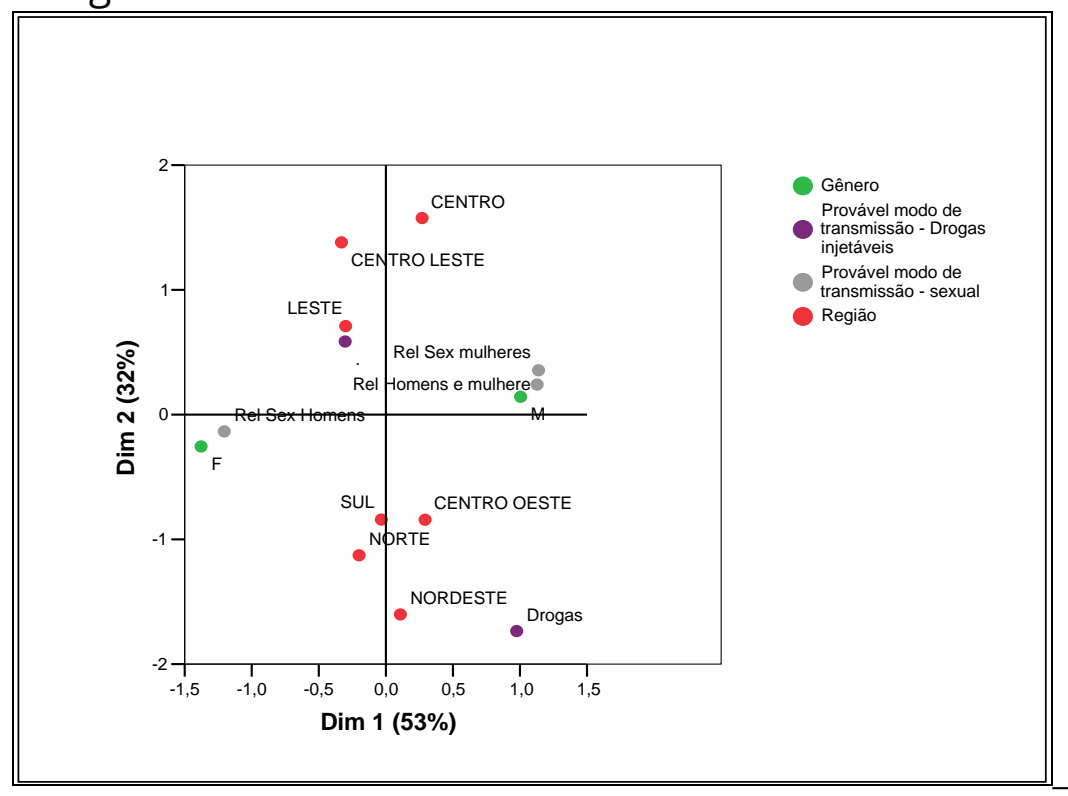

Legenda: [Gênero: $F$ (feminino) e M (masculino)], [Provável modo de transmissão - Drogas: Sim], [Provável modo de transmissão - sexual: (Relação Sex Homens: relação sexual somente com homens, Rel Sex mulheres: relação sexual somente com mulheres, Rel Homens e mulheres: relação sexual com homens e mulheres], [região: divisão administrativa por regiões da cidade].

O mapa de correspondência apresentado na Figura 04 demonstra em duas dimensões um percentual de $82 \%$ da dimensionalidade de explicação dos dados expostos. Na dimensão 1 a variável que mais influencia é o gênero, seguido do provável 
modo de transmissão - sexual. Já para a dimensão a variável com maior fator é a região seguido do provável modo de transmissão - drogas.

Ao analisar a Figura 5, podemos verificar uma divisão em duas zonas. A porção negativa da dimensão 1 abriga categorias relacionadas ao sexo feminino e que têm relação sexual com homens. Em contrapartida, a parte positiva do eixo engloba características de serem homens, com relação sexual com mulheres e relação sexual com homens e mulheres, que residem no centro da cidade. Na Figura ainda visualizase que os usuários de drogas estão associados às regiões: nordeste, centro leste e sul. A região leste não está relacionada a nenhum tipo de público específico, ficando em um quadrante separada das demais características.

Na Figura 6 verificam-se as relações existentes entre as variáveis gênero, idade, provável modo de transmissão.

Figura 6 - Mapa de correspondência múltipla - Variáveis: gênero, idade, provável modo de transmissão

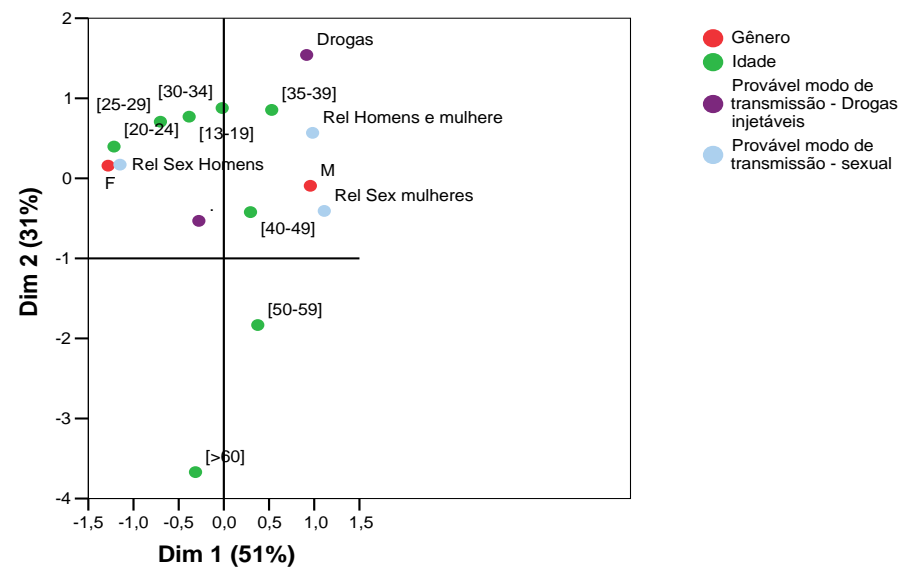

Legenda: [Gênero: F (feminino) e M (masculino)], [idade: faixas etárias], [Provável modo de transmissão - Drogas: Sim], [Provável modo de transmissão - sexual: (Rel sex Homens: relação sexual somente com homens, Rel Sex mulheres: relação sexual somente com mulheres, Rel Homens e mulheres: relação sexual com homens e mulheres).]

No mapa de correspondência apresentado na Figura 6, verifica-se uma dimensionalidade de $82 \%$ de explicação dos dados analisados. A dimensão 1 é representada em grande parte pela variável gênero e a dimensão 2 pela variável idade.

Um grupo de pacientes bem definidos são os homens na faixa etária de [35-49] anos, usuários de drogas e que têm relação sexual com homens e mulheres ou apenas relação com mulheres. No outro quadrante, são encontradas as mulheres na faixa 
etária de [13 a 34] anos, que têm relação sexual com homens. As faixas etárias maiores que 50 anos não estão relacionadas a nenhum tipo de abordagem com essas variáveis.

Figura 7 - Mapa de correspondência múltipla - Variáveis: escolaridade, gênero, idade e região

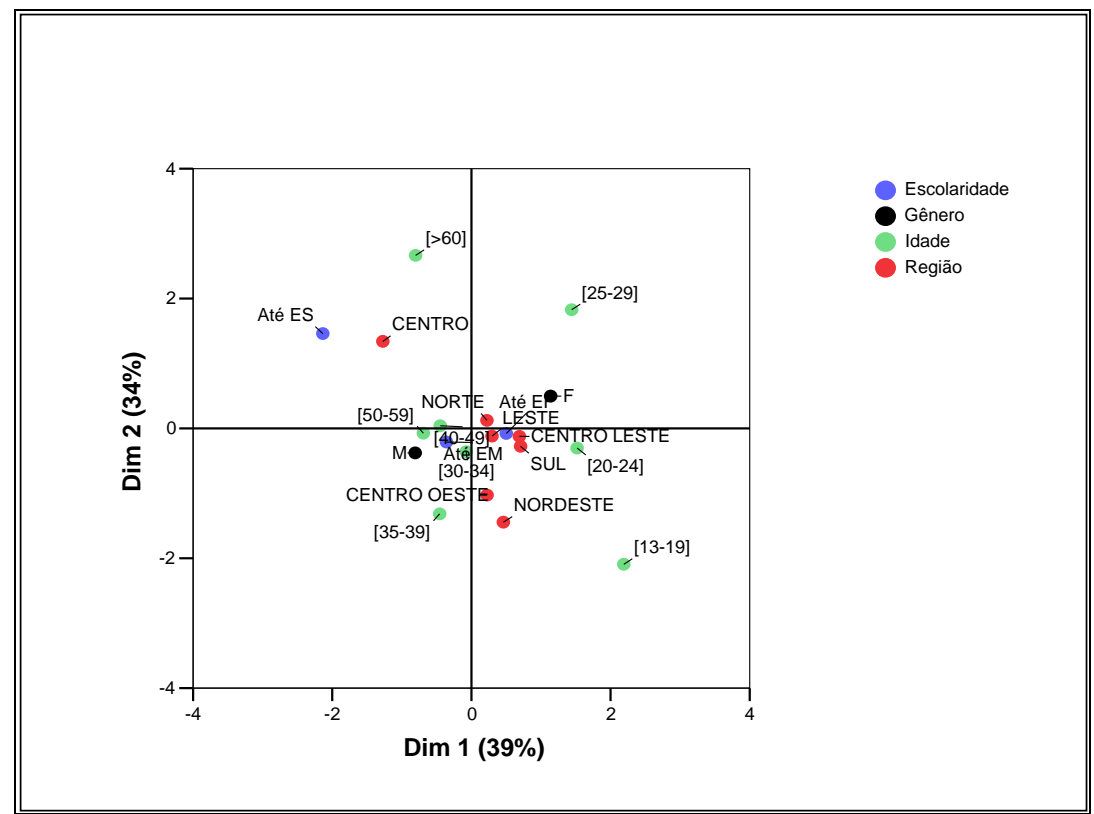

Legenda: [Escolaridade: Até EF: Com ensino fundamental completo ou incompleto, Até EM: Ensino médio completo ou incompleto e até ES: Ensino superior completo ou incompleto],[Gênero: $F$ (feminino) e M (masculino)], [idade: faixas etárias], [região: divisão administrativa por regiões da cidade].

Na Figura 7, verifica-se o mapa de correspondência para as variáveis: escolaridade, gênero, idade e região, representada por $73 \%$ da variabilidade nas duas dimensões expostas. A dimensão 1 é representada pela variável gênero e a dimensão 2 pela variável idade.

As mulheres têm uma associação com ensino fundamental na região leste e a faixa etária de [25-29] anos, e os homens associados ao ensino médio [30-49] na região centro oeste. Além disso, no mesmo quadrante encontram-se pessoas acima de 60 anos, com ensino superior do centro da cidade. 
Figura 8 - Mapa de correspondência múltipla - Variáveis: evolução, gênero e região

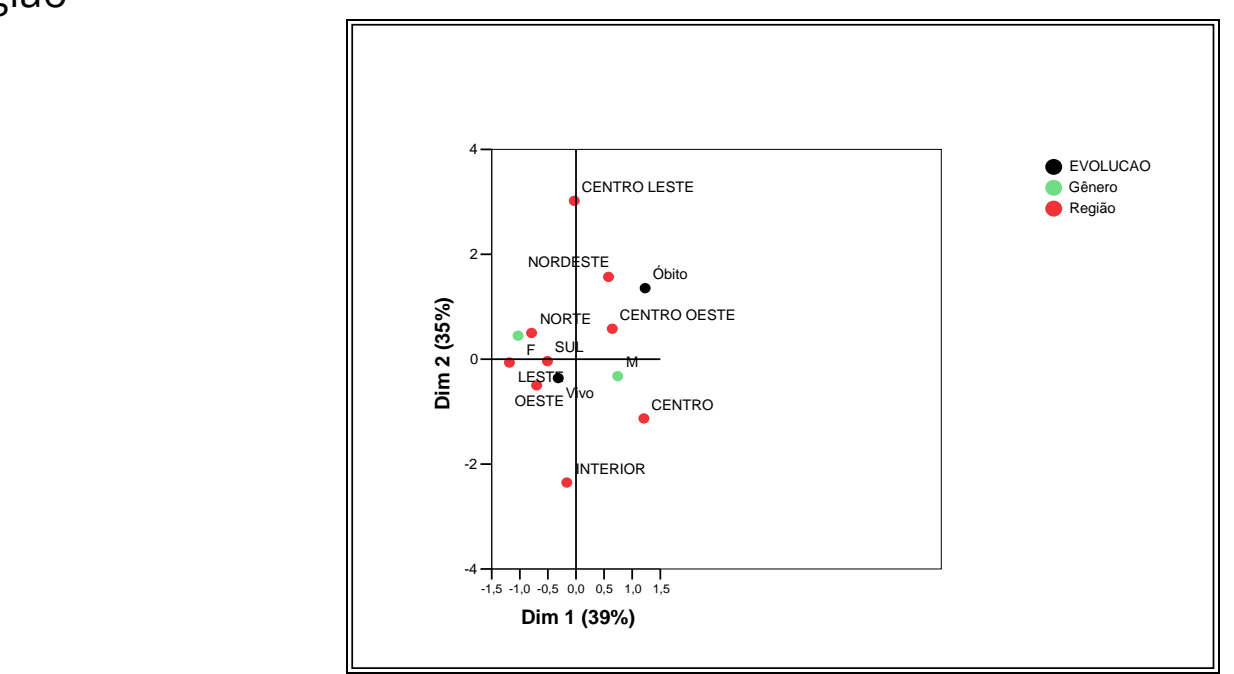

Legenda: [Evolução: vivo em 31/12/2013, óbito em 31/12/2013], [Gênero: F (feminino) e M (masculino)], [região: divisão administrativa por regiões da cidade].

O mapa de correspondência que associa as variáveis evolução do caso, gênero e região (apresentado na Figura 8) tem uma explicação de 74\% do banco de dados, sendo que a dimensão 1 é representada em sua maioria pelo gênero e a dimensão 2 pela região de residência do paciente.

Ainda em relação à Figura 07 , verifica-se que os pacientes que estavam com status vivo no último dia de pesquisa, 31/12/2013, estão relacionados a pertencer a região leste, oeste ou interior e ser do sexo feminino. Do lado oposto da dimensão 1 , os pacientes que vieram a óbito depois de serem diagnosticados com AIDS estão associados a residir na região nordeste e centro leste.

\section{CONSIDERAÇÕES FINAIS}

Com o este estudo, identificou-se o perfil dos pacientes, em na sua maioria, do sexo masculino de raça branca, com média de idade de $38,08( \pm 11,01)$ anos, com escolaridade prevalente ensino fundamental incompleto e moradores da zona urbana. Quanto às condições de saúde, a maioria deles apresentava contagem de CD4+ inferior a 350 células $/ \mathrm{mm}^{3}$ em que o tratamento anti-retroviral é recomendado. Todos os pacientes apresentaram alguma doença oportunista relacionada ao HIV/AIDS. A principal forma de infecção, de acordo com os pacientes diagnosticados, foi por relação sexual. A distribuição dos casos é regular entre o sexo feminino e o masculino, e a faixa etária com maior número de casos é de 30-39 anos. 
A região com maior incidência de casos de AIDS na cidade de Santa Maria é a Região Oeste. Observa-se que a maioria dos casos de AIDS foram diagnosticados no ano de 2010.

A técnica de análise de correspondência múltipla (ACM) provou ser uma ferramenta válida para avaliar as associações presentes entre as variáveis categóricas, mostrando a estrutura dos dados de forma gráfica, com fácil visualização das posições das categorias. Seus resultados indicaram ainda variáveis importantes para a diferenciação entre os serviços de farmácia hospitalar, podendo ser estas utilizadas em estudos futuros na construção de questionários concisos.

Avaliando-se os resultados da ACM, as mulheres estão associadas à raça preta e na região sul do mapa. O sexo masculino está associado à região leste, nas faixas etárias [40 - 59] anos e de raça branca.

Quanto ao sexo feminino, existe associação com a relação sexual com homens, já para os homens, a associação está relacionada a ter relação sexual com mulheres e relação sexual com homens e mulheres, que residem no centro da cidade, os usuários de drogas estão associados às regiões: nordeste, centro leste e sul.

Um grupo de pacientes bem definidos são os homens na faixa etária de [35-49] anos, usuários de drogas e que têm relação sexual com homens e mulheres ou apenas relação com mulheres. As mulheres na faixa etária de [13 a 34] anos, que têm relação sexual com homens.

As mulheres têm uma associação com ensino fundamental na região leste e a faixa etária de [25-29] anos, e os homens associados ao ensino médio [30-49] na região centro oeste. Além disso, no mesmo quadrante encontram-se pessoas acima de 60 anos, com ensino superior do centro da cidade.

Com este trabalho foi possível identificar a faixa etária e sexo de maior incidência bem como o número de casos por regiões, com isso será possível de trabalhar na promoção da saúde para toda a população, visando incentivar à realização do teste anti-HIV e reforçar constantemente a importância do uso da camisinha, com campanhas direcionadas a todos os públicos. 


\section{REFERÊNCIAS}

ADIMORA AA, SCHOENBACH VJ. Social context, sexual networks, and racial disparities in rates of sexually transmitted infections. The Journal of Infectious Diseases. 2005;191 (Suppl 1):S115-122.

MINISTÉRIO DA SAÚDE [Internet]. Brasília: Ministério da Saúde [cited em 2015 feb 27]. A Saúde no Brasil: indicando resultados 1994 - 2001. Série C: Projeto, Programas e Relatórios. Brasília. Available from: http://bvsms.saude.gov.br/bvs/publicacoes/saude_Brasil.pdf.

MINISTÉRIO DA SAÚDE; Programa Nacional de DST e Aids (2003). Aids-Boletim Epidemiológico. Ano XVII n01- Editora do Ministério da Saúde. Brasília (Brasil): Ministério da Saúde; 2008.

MINISTÉRIO DA SAÚDE; Departamento de DST, Aids e Hepatites Virais/SVS/MS. AidsBoletim Panorama da AIDS no Brasil.Editora do Ministério da Saúde. Brasília (Brasil): Ministério da Saúde; 2012.

MINISTÉRIO DA SAÚDE; Boletim epidemiológico - Aids e DST 2011. Brasília (Brasil): Ministério da Saúde; 2012.

CLAUSEN, SE. Applied correspondence analysis: an introduction. Quantitative Applications in the Social Sciences. Thousand Oaks: CA: Sage University Papers Series; 1998.

COELHO N. Ministério da Saúde estende tratamento para todos com HIV [internet]. Ministério da Saúde: Departamento de Condições Crônicas e Infecções Sexualmente Transmissíveis; 2013 Dec 01 [cited 2015 Apr 02], Available from: http://www.aids.gov.br/noticia/2013/ministerio-da-saude-estende-tratamento-paratodos-com-hiv.

CZERMAINSKI AB. Análise de correspondência. Piracicaba; 2004 [cited 2008 jul 10]. Available from: http://ce.esalq.usp.br/tadeu/anabeatriz.pdf.

DIEZ-ROUX AV. Bringing context back into epidemiology: variables and fallacies in multilevel analysis. Am J Public Health. 1998;88 (Suppl 2):216-222.

GIL AC. Como elaborar projetos de pesquisa. 5th ed. São Paulo: Atlas, 2008.

GREENACRE MJ. Practical Correspondence Analysis. In: Barnett V, editor. Looking at Multivariate Data. New York: J. Wiley \& Sons. 1981. 
KNOP MNH. A escolha de curso superior dos vestibulandos da Universidade Federal do Rio Grande do Sul: um estudo quantitativo com utilização de Análise de Correspondência Múltipla. Porto Alegre: Universidade Federal do Rio Grande do Sul/UFGRS; 2008.

KUO JM, TAYLORJMG, DETELS R. Estimating the AIDS incubation period from a prevalent cohort. American Journal of Epidemiology. 1991;133:1050-1057.

LABOISSIÈRE P. Descoberta da aids completa $\mathbf{3 0}$ anos [Internet]. Juiz de Fora: Universidade Federal de Juiz de Fora; 2015 Jun [cited em 2015 jul 10]. Available from: https://www.ufjf.br/ladem/2011/06/07/descoberta-da-aids-completa-30-anos/.

LEI FEDERAL N.9.313/96 DE 13 DE NOVEMBRO 1996. Dispõe sobre a distribuição gratuita de medicamentos aos portadores do HIV e doentes de AIDS. Diário Oficial da União (Brasília). 1996. Nov 14.

LOURENÇO EB. Análise de correspondência: Contribuições para a avaliação do docente. Campinas: Universidade Estadual de Campinas/Unicamp; 1997.

MANDAL A. "História do AIDS."; 2014 [cited 2015 Apr 27], Available from http://www.news-medical.net/health/History-of-AIDS-(Portuguese).aspx.

MARQUES P. Televisão e Aids: análise dos filmes publicitários do Ministério da Saúde dos carnavais de 1996 a 1999. Universidade de Marília; 2008. 135p.

MATGE PR. Santa Maria bate recorde da década em notificações de casos de HIV. Diário de Santa Maria [internet]. 2017 Dec 03 [cited 2010 feb 01]. Saúde. Available from: https://diariodesantamaria.atavist.com/hiv.

MINAYO MC. $O$ desafio do conhecimento: pesquisa qualitativa em saúde. 14th ed. Rio de Janeiro: Hucitec; Abrasco; 2010.

MOTA JC, VASCONCELOS AGG, ASSIS SG. Análise de correspondência como estratégia para descrição do perfil da mulher vítima do parceiro atendida em serviço especializado. Ciência \& Saúde Coletiva. 2007:12(3):799-809.

NETO AAO. Metodologia da Pesquisa Cientifica, guia prático para a apresentação de trabalhos acadêmicos. 2nd ed. Florianópolis: Visual Books Editora Ltda; 2006.

RIBEIRO RC. Análise do desempenho econômico financeiro das seguradoras do Grupo dos seguros de riscos patrimoniais: Associação entre seguradoras e indicadores. 2011. 54f. [Monography]. Rio de Janeiro:Especialização em Finanças e Gestão Corporativa/ Universidade Candido Mendes; 2011. 
RODRIGUES AL, CASTILHO E. A epidemia de Aids no Brasil, 1991-2000: descrição espaço-temporal. Revista da Sociedade Brasileira de Medicina Tropical. 2004; 37(4):312-317.

SANCHES KRG. A AIDS e as mulheres jovens: uma questão de vulnerabilidade. Rio de Janeiro: Escola Nacional de Saúde Pública/ Fundação Oswaldo Cruz; 1999. 194p.

SECRETARIA ESTADUAL DE SAÚDE DO RIO GRANDE DO SUL. Ministério da Saúde. Linha de Cuidado para Pessoas Vivendo com HIV/Aids (PVHA) e outras DST. Coordenação Estadual de DST/Aids, 2014. 54p.

VARELLA D. Epidemia de AIDS no Brasil [Internet]. 2011 abr 20 [cited 2015 apr 29]. Available from: http://drauziovarella.com.br/sexualidade/aids/epidemia-da-aids-nobrasil/

VIERO LM, FIGUEIREDO VD. Uma Avaliação da População do Município de Santa Maria (RS): ênfase para as unidades distritais, 2000-2010. In: Anais do XVIII Encontro Nacional de Estudos Populacionais, ABEP; 2012; Águas de Lindóia, Brasil.

WORLD HEALTH ORGANIZATION (WHO) [internet]. Genebra. [cited 2013 jan 07]. Diminuindo diferenças: a prática das políticas sobre determinantes sociais da saúde. Available from: www.who.int/ sdhconference/discussion_paper/Discussion_Paper_PT.pdf. 